\title{
Psychometric properties of the WHOQOL-SRPB BREF, Brazilian Portuguese version
}

\author{
Rogério R. Zimpel, ${ }^{1,2}$ iD Raquel G. Panzini, ${ }^{1,3}$ Denise R. Bandeira, ${ }^{4}$ Marcelo P. Fleck, ${ }^{1,2}$ \\ Neusa S. da Rocha ${ }^{1,2}$ \\ ${ }^{1}$ Programa de Pós-Graduação em Psiquiatria e Ciências do Comportamento, Universidade Federal do Rio Grande do Sul (UFRGS), Porto \\ Alegre, RS, Brazil. ${ }^{2}$ Hospital de Clínicas de Porto Alegre (HCPA), Porto Alegre, RS, Brazil. ${ }^{3}$ Secretaria da Saúde do Estado do Rio Grande do \\ Sul, Porto Alegre, RS, Brazil. ${ }^{4}$ Programa de Pós-Graduação em Psicologia, UFRGS, Porto Alegre, RS, Brazil.
}

\begin{abstract}
Objective: To test the reliability and the discriminant and convergent validity of the abbreviated Brazilian Portuguese World Health Organization's Quality of Life Instrument - Spirituality, Religion, and Personal Beliefs module (WHOQOL-SRPB BREF).

Methods: In a sample of 404 individuals, we applied a general questionnaire, the WHOQOL-BREF, the long-form SRPB, the Brief Religious-Spiritual Coping Scale (RCOPE), and the Beck Depression Inventory (BDI). Priority was given to the 9-item SRPB assessment: its unidimensionality was tested through confirmatory factor analysis and Rasch analysis.

Results: Confirmatory factor analysis of the 9-item SRPB assessment indicated an adjusted model with acceptable fit to data. In the Rasch analysis, general fit measures showed adequate performance. The 9-item SRPB assessment showed good internal consistency (alpha $=0.85$ ), and could differentiate (discriminant validity) between religious and atheist/agnostic respondents (mean $=74.7 \pm 14.1$ and 56.8 \pm 15.5 , respectively; $t=6.37$; degrees of freedom [df] $=402 ; p<0.01$ ) and between nondepressed and depressed respondents (mean $=76.5 \pm 12.9$ and 67.1 $\pm 16.5 ; t=5.57$; $\mathrm{df}=190.5$; $p<0.01)$. Correlations (convergent validity) were significant with the positive-RCOPE subscale $(r=0.58, p<0.01)$ and the WHOQOL-BREF domains (Pearson coefficient ranging between 0.24 and $0.49 ; p<0.01)$, but were in the negative direction with the negative-RCOPE subscale $(r=-0.10$, $p<0.05)$. Correlation with the long-form SRPB domain $(r=0.934)$ was almost perfect.

Conclusion: The Brazilian Portuguese 9-item SRPB has good psychometric properties and confirmed the findings of the long-form Brazilian Portuguese version and the abbreviated English version.
\end{abstract}

Keywords: Spirituality; religiousness; spiritual QoL; WHOQOL-SRPB BREF; psychometrics

\section{Introduction}

The World Health Organization (WHO) defines quality of life (QoL) as "the individual's perception of their position in life within the cultural context and system of values in which they live and in relation to their goals, expectations, standards and concepts." The WHOQOL-100, the generic version of the WHO Quality of Life (WHOQOL) measure, has six domains: physical, psychological, independence, social, environmental, and spirituality. The basic Spirituality, Religion, and Personal Beliefs (SRPB) domain contains only four items. ${ }^{1}$ These items were found insufficient to measure this domain's complexity. ${ }^{2}$ To address this limitation, the WHOQOL group first decided to expand this dimension and then established a cross-cultural assessment of spiritual QoL that could be used to assess not only adherents of the major world religions but also diverse personal and spiritual beliefs worldwide. ${ }^{3}$ As a result, the

Correspondence: Rogério R. Zimpel, Av. Protásio Alves, 1281/204, CEP 90410-001, Porto Alegre, RS, Brazil.

E-mail: rogerio.zimpel@gmail.com

Submitted Mar 09 2018, accepted Oct 16 2018, Epub Apr 152019.
WHOQOL-SRPB measure contains 132 items, consisting of 32 SRPB items plus the complete WHOQOL-100. ${ }^{4}$

Shorter assessments are easier to apply and faster to score and interpret; hence, their availability may encourage more frequent use in academic and healthcare services. ${ }^{4}$ With the aim of developing a short-form measure for generic use that also contains questions about QoL related to SRPB, Skevington et al. ${ }^{4}$ analyzed data from the 132 international items of the WHOQOL-SRPB $(n=5,087)$, contributed by 18 cultures worldwide. ${ }^{3}$ From this pool, they selected the single best item in psychometric terms from each of eight newly developed facets in the WHOQOL-SRPB and combined them with the 26 items of the WHOQOL-BREF. The WHOQOL-BREF items had been previously extracted from the WHOQOL-100 to provide an abbreviated version. ${ }^{5}$ The 34 items of the WHOQOL-SRPB BREF are scored as five QoL domains: 1) physical, 2) psychological, 3) social, 4) environmental, 
and 5) SRPB. The SRPB domain in the WHOQOL-SRPB BREF consists of nine items: one from the original WHOQOL-BREF plus eight new items. The preliminary psychometric properties of the WHOQOL-SRPB BREF were tested by Skevington et al. ${ }^{4}$ They indicated that the WHOQOL-SRPB BREF can be used wherever such translations exist; for example, the Brazilian version is one of the 18 cultures in the international sample that was part of the WHOQOL-SRPB study. Although the WHOQOL-BREF shows good international reliability and validity, ${ }^{6}$ as well as responsiveness to clinical and social change ${ }^{7}$ it is important to evaluate the way in which the new 9-item SRPB module behaves in a Brazilian population sample, since the Brazilian Portuguese version of the 26-item WHOQOL-BREF has already been validated and is extensively used in healthcare settings. ${ }^{8}$

To date, no assessments of the psychometric properties of 9-item SRPB in languages other than English have been published. The English version of the 9-item SRPB demonstrated a Cronbach's alpha of 0.83 and acceptable convergent validity. ${ }^{4}$ Only the long-form WHOQOL-SRPB has been validated in Brazilian Portuguese, which consists of the 26-item WHOQOL-BREF plus the specific SRPB domain (totaling 32 -items). ${ }^{9}$ The 32-item long-form SRPB domain showed good internal consistency (Cronbach's alpha $=0.96$ ) and satisfactory discriminant and convergent validities when applied in a Brazilian sample. ${ }^{9}$

The aim of the present study was to extract the Brazilian Portuguese 9-item SRPB from the Brazilian Portuguese long-form WHOQOL-SRPB validation database $^{9}$ and test its unidimensionality through confirmatory factor analysis and Rasch analysis to assess whether it continues to form a single domain. In addition, the 34-item WHOQOL-SRPB BREF was tested for its reliability and discriminant and convergent validity. Our hypotheses were that the Brazilian Portuguese 9-item SRPB would confirm its unidimensionality and that all 34 items of the WHOQOL-SRPB BREF will present good psychometric properties due to the cross-cultural nature of the WHOQOL group's instruments. ${ }^{4}$

\section{Methods}

\section{Sample}

In this cross-sectional study, a convenience sample was paired for gender, age, and health status (50\% male, $50 \%<45$ years, and $50 \%$ unhealthy). The patient group consisted of hospitalized patients and outpatients from a university hospital in Porto Alegre, state of Rio Grande do Sul, Brazil, from different clinical areas (cardiology, oncology, pneumology, endocrinology, rheumatology, ophthalmology, nephrology and neurology). The healthy group consisted of hospital and university staff who responded negatively to questions about: 1 ) regular medication use; 2) having visited the doctor in the last month; and 3) having been clinically diagnosed with a disease. The sample represented different educational and socioeconomic levels and the religious/spiritual belief profiles of Porto Alegre, which were proportional to the number of adherents (e.g., Catholic, Protestant, Spiritist, etc.) and atheists/agnostics in the state population, ${ }^{10}$ with no statistical adjustments made regarding minimum numbers of individuals per group.

The inclusion criteria involved several parameters: 1 ) voluntary participation; 2) $\geqslant 18$ years; 3 ) having a minimum of 2 years of elementary school; 4) being able to fill out self-administered instruments (alone or with the help of a trained researcher for the visually impaired or those with physical disabilities limiting their ability to write).

Individuals were consecutively invited to participate according to availability, inclusion criteria, and the number of participants required for each criterion group. Excess completed cases collected by different researchers were included. Due to logistical reasons, hospitalized patients were given priority. Individuals involved in data collection were instructed to include patients with the greatest diagnostic diversity in the different specialties available in the hospital. A diversified sample for the healthy group was also selected, including personnel with different levels of authority from distinct hospital and university sectors. In general, patients were given from 1 to 3 days to return the completed protocol, while healthy employees were given from 1 to 2 weeks to complete it at home, due to the lack of free time at work. The sample was obtained over 3 years and refusals totaled $7 \%$.

The study was approved by the research ethics committee of the Hospital de Clínicas de Porto Alegre (protocol 05-180). Participants were asked to provide written informed consent and, after agreeing to participate, they responded to a general questionnaire and four scales, which are described in the following sections.

\section{Instruments}

\section{General questionnaire}

The general questionnaire involved the following aspects: 1) demographics (age, gender, education, socioeconomic status, marital status, origin, and occupation); 2) health status (quality, category, current problem, medication, consultations, diagnosis, and treatment); and 3) religion (belief in God, participant's religion/beliefs, help from religion/spirituality for stressful situations, importance of religion, frequency of attendance at religious services, and frequency of private religious activities such as prayer, meditation, and reading).

World Health Organization Quality of Life Instrument Abbreviated version (26-item WHOQOL-BREF)

This instrument includes 26 items in four domains and has a global score, as well as a specific score for each domain. Its internal consistency is alpha $=0.91$ and should be between 0.69 and 0.84 for each domain. The global score does not refer to the mean of the domains, but rather to the mean of two items not belonging to the four domains (global health and global QoL). It was translated and validated for Brazilian Portuguese by Fleck et al. ${ }^{8}$ 
The long-form Spirituality, Religion, and Personal Beliefs domain

The specific SRPB domain consists of 32 items distributed in eight facets: spiritual connection; meaning and purpose in life; experiences of awe and wonder; wholeness and integration; spiritual strength; inner peace; hope and optimism; and faith. This instrument generates one general domain score and eight factorial structures. Factorial analysis (analysis of main components by varimax rotation and Kaiser normalization) of the Brazilian Portuguese version of the WHOQOL-SRPB resulted in eight factors, which explained $74.1 \%$ of the variance: factor 1) faith, spiritual strength; factor 2) inner peace; factor 3) spiritual connection; factor 4) hope and optimism; factor 5) meaning and purpose in life; factor 6 ) (half of the items) experiences of awe and wonder; factor 7) (half of the items) wholeness and integration; (half of the items) experiences of awe and wonder; and factor 8 (half of the items) wholeness and integration. Joint exploratory factorial analysis of the WHOQOLSRPB and WHOQOL-BREF with the same parameters resulted in 1 factor that explained $63.6 \%$ of the variance. The WHOQOL-SRPB was grouped into four factors that are distinct from the six factors used to organize the WHOQOL-BREF items. When SRPB domain 6 from the WHOQOL-100 was added to the WHOQOL-SRPB, it was grouped in the fourth factor: meaning and purpose in life. ${ }^{9}$ The domain's internal consistency is alpha $=0.96$ (intrafactorial correlation between 0.60 and 0.87 ) with excellent test-retest reliability $(t=0.74 ; p=0.463)$. Fivepoint Likert scales ( $1=$ none to $5=$ completely) are used for the responses. ${ }^{9}$ Some examples include: "To what extent do you feel your life has a purpose?"; "To what extent does faith give you comfort in daily life?"; and "How much does spiritual strength help you live better?"

Nine-item Spirituality, Religion, and Personal Beliefs assessment

This instrument includes the eight items with the best psychometric performance from the 32-item WHOQOLSRPB, according to a validation by Skevington et al. ${ }^{4}$ The ninth item was taken from the WHOQOL-BREF (which, in turn, originates from the WHOQOL-100/SRPB domain). Data on the 9-item SRPB was extracted from the Brazilian Portuguese long-form WHOQOL-SRPB validation database. ${ }^{9} \mathrm{~A}$ detailed description of the translation and cultural adaptation procedures for these items can be found elsewhere. ${ }^{11}$ The Brazilian Portuguese version of the 9-item SRPB is shown in Box 1.

\section{The Brief Religious-Spiritual Coping Scale (RCOPE)}

Coping is the set of strategies people use to handle stressful situations. The Brief RCOPE Scale evaluates the spiritual/religious strategies individuals use to handle the most stressful situation they faced in the last 3 years, about which participants respond according to a five-point Likert scale (1-not at all; 5-very much). The Brazilian Portuguese version of the RCOPE ${ }^{12}$ includes 49 items divided into two dimensions: 1) a positive religious coping subscale (positive-RCOPE), with 34 items and eight
Box 1 The Brazilian Portuguese 9-item Spirituality, Religiousness, and Personal Beliefs assessment

wq6)* Em que medida você acha que a sua vida tem sentido?

Sp1.1) Até que ponto alguma ligação a um ser espiritual ajuda você a passar por épocas difíceis?

Sp2.3) Até que ponto você sente que a sua vida tem uma finalidade?

Sp8.2) Até que ponto a fé lhe dá conforto no dia a dia?

Sp7.2) Até que ponto você está esperançoso com a sua vida?

Sp3.1) Até que ponto você consegue ter admiração pelas coisas a seu redor? (por exemplo: natureza, arte, música)

Sp5.3) O quanto a força espiritual o ajuda a viver melhor?

Sp6.2) Até que ponto você tem paz interior?

Sp4.2) Quão satisfeito você está por ter um equilíbrio entre a mente, o corpo e a alma?

The SRPB domain must be applied together with the four WHOQOL-BREF domains.

* World Health Organization Quality of Life (WHOQOL-BREF) spirituality item.

facets/factors; and 2) a negative religious coping subscale (negative-RCOPE), with 15 items and four facets/factors. It has an internal consistency of alpha $=0.93$ (positiveRCOPE alpha $=0.95$; alpha $=0.79$ ). The positive-RCOPE subscale includes coping strategies that provide beneficial/positive effects for the practitioner, such as looking for God's love/protection and greater connection with transcendental forces, etc. (e.g.: "Did my best and then turned the situation over to God"). The negative-RCOPE subscale includes coping strategies that have harmful/ negative consequences for the individual, such as questioning the existence, love or actions of God, passively waiting for God to solve problems, etc. (example of item: "Didn't do much, just expected God to solve my problems for me"). The Brief RCOPE Scale was translated, adapted, and validated for Brazilian Portuguese by Panzini \& Bandeira. ${ }^{13}$

\section{Beck Depression Inventory (BDI)}

This inventory consists of 21 questions about depressive symptomatology whose score is obtained from the sum of the items (0 to 63). Its internal consistency varies between 0.70 and 0.92 for non-clinical, medical-clinical, and psychiatric samples. It was translated and validated for Brazilian Portuguese by Cunha. ${ }^{14}$

\section{Statistical analysis - 9-item SRPB}

The structural equation model (SEM) was used to analyze the factorial structure and goodness-of-fit measures. Maximum likelihood was the estimation method used for SEM. Goodness-of-fit statistics included chi-square (ideally, it should not be significant, that is, $p>0.001$ ), comparative fit index (CFI) with values close to 1 (which indicate a good fit), root mean square error of approximation (RMSEA) with a value of 0 (which indicates a perfect fit), goodness of fit index (GFI) with values close to 1 (which indicates a perfect fit), and root mean square residual (RMSR) with a value of 0 (which indicates a perfect fit). ${ }^{15,16}$ The best fit of a model is defined by analyzing some diagnoses, such as standardized loadings (which 
must not be $<0.5$ ), standardized residuals (which should be $<2.5)$, and the modification index (MI), which must not be $>4$. The result is a combination of these diagnoses and is obtained through statistical analyses with computer programs. Identification of the highest MI values shows paths identified through analysis of the variation in error covariance to better fit the model. ${ }^{17,18}$

Rasch analysis was used to assess the unidimensionality of the scale, and the results were examined using goodness-of-fit measures. In the Rasch analysis, residuals $>2.5$ with a significant chi-square score $(p<0.05)$ are considered unacceptable. Items with problematic residuals are excluded from the analysis, and the analysis is performed again to verify if this procedure improved the fit. Rasch analysis considers six general statistics to determine the model's fit. Four are item-person interaction statistics with $Z$ statistical distribution (mean [M] and standard deviation [SD]) in which values equal to 0 and a SD equal to 1 indicate perfect fit for the model. The final two fit statistics are item-trait interactions with the total item chi-square, which must present a low score and a nonsignificant $p$-value $(p<0.05)$ for a good fit to the Rasch model. ${ }^{19,20}$

The instrument's responsiveness was evaluated through floor/ceiling effect. A floor/ceiling effect occurs when more than $20 \%$ of participants choose the lowest or highest possible score of the scale item, which is not desirable. Regarding missing data, a good item should have a maximum of $5 \%$ non-responses. ${ }^{21}$

Internal consistency was measured using Cronbach's alpha. A higher coefficient indicates a more reliable instrument. A value $>0.70$ is considered adequate. ${ }^{22}$ Discriminant validity between believers and atheists/agnostics, non-depressed and depressed individuals, and healthy and unhealthy individuals was assessed using a $t$-test. It was expected that the 9-item SRPB scores would be different between these groups. Convergent validity was assessed using Pearson's correlation between 9-item SRPB and the long-version SRPB domain (without the eight items used in the 9-item SRPB) and other valid religiosity/spirituality and QoL measures, such as the positive/negative-RCOPE subscales and the WHOQOLBREF (without the item included the 9-item SRPB), respectively. It was expected that these measures, except for the negative-RCOPE subscale, would be positively correlated with 9-item SRPB scores.

The basic descriptive statistical analysis was performed using: 1) RUMM2020 for the Rasch analysis; 2) AMOS 4.01 for confirmatory factor analysis; and 3) SPSS version 18.0 for classical psychometric analysis.

\section{Results}

\section{Sample}

The sample consisted of 404 individuals, who were mostly female ( $n=213 ; 52.7 \%)$, healthy, white, married, Catholic, from the second-highest social class, high school graduates, employed, and residents of Porto Alegre. Their ages ranged from 18 to 84 years ( $M=42.85 \pm 13.91$ years). Based on the proportions of religious/spiritual beliefs in
Porto Alegre's population, six groups were created, in addition to an atheist/agnostic group (i.e., those who do not believe in God or have doubts about His existence) (Table 1).

\section{SRPB BREF: psychometric properties}

\section{Confirmatory factor analysis}

Confirmatory factor analysis was performed with SEM to test the unifactorial model of the 9-item SRPB assessment. The unadjusted model showed some indices that could be improved $\left(\mathrm{CFI}=0.73 ; \chi^{2}=448.93\right.$; $\mathrm{df}=27$; RMSEA $=0.20$; RMR $=0.09 ; p=0.00$ ). Several adjustments resulted in significant improvement of the unifactorial indices for the model $\left(\chi^{2}=23.14 ; \mathrm{df}=16 ; \mathrm{CFI}=\right.$ 0.99; $\mathrm{GFI}=0.99$; $\mathrm{RMSEA}=0.03 ; \mathrm{RMR}=0.02 ; \mathrm{p}=0.11$ ), as shown in Figure 1.

Table 1 Demographic data $(n=404)$

\begin{tabular}{lc}
\hline Variable & $\mathrm{n}(\%)$ \\
\hline Age (years) & \\
$18-44$ & $219(54.2)$ \\
45 and more & $185(45.8)$ \\
Sex & \\
Female & $214(53)$ \\
Male & $190(47)$ \\
Health status & \\
Healthy & \\
Unhealthy & $207(51.2)$ \\
& $197(48.8)$ \\
Education level & \\
Primary education & \\
Secondary education & $110(27.2)$ \\
Higher education & $175(43.3)$ \\
Postgraduate studies & $96(23.8)$ \\
Socioeconomic level* (class) & $24(5.7)$ \\
A & \\
B & $26(6.4)$ \\
C & $192(47.6)$ \\
D & $156(38.6)$ \\
E & $26(6.4)$ \\
Marital status & $4(1)$ \\
Married/living as married & \\
Single & \\
Separated/divorced & $214(53)$ \\
Widowed & $110(27.2)$ \\
Ethnicity & $63(15.6)$ \\
White & $17(4.2)$ \\
Black & \\
Mixed & $278(69.2)$ \\
Indigenous & $66(16.4)$ \\
Beliefs & $50(12.4)$ \\
Catholic & $8(2)$ \\
Protestant & \\
Spiritist & \\
Afro-Brazilian & \\
Other religions & $67(16.6)$ \\
Spiritual without organized religion & $34(8.4)$ \\
Atheist/agnostic & $25(6.2)$ \\
\hline Brazlan socioeconomic critera \\
\hline
\end{tabular}

\footnotetext{
* Brazilian socioeconomic criteria. ${ }^{23}$
} 


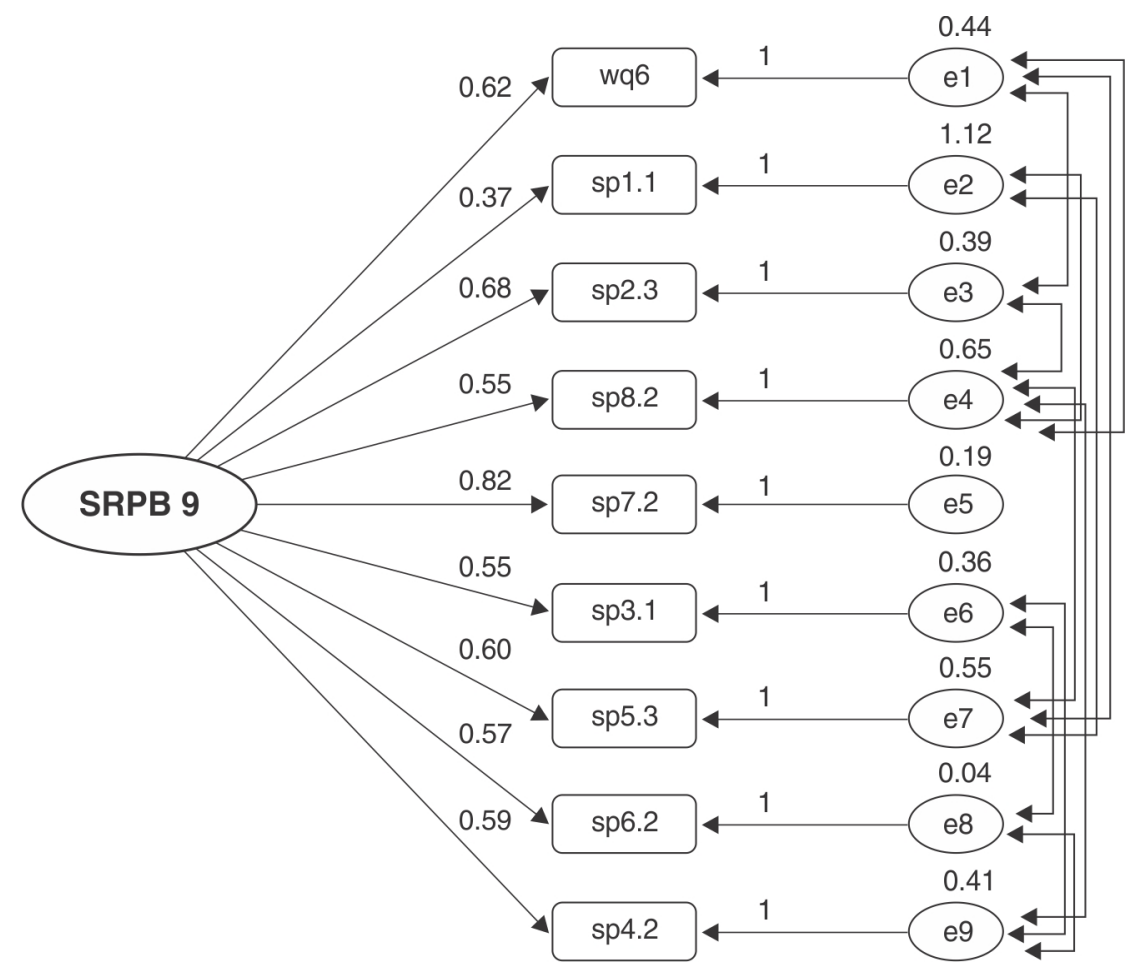

Figure 1 Confirmatory factor analysis model after adjustment. Sp1.1 = To what extent does any connection to a spiritual being help you to get through hard times?; Sp2.3 = To what extent do you feel your life has a purpose?; Sp3.1 = To what extent are you able to experience awe from your surroundings? (e.g. nature, art, music); Sp4.2 = How satisfied are you that you have a balance between mind, body and soul? Sp5.3 = How much does spiritual strength help you live better?; Sp6.2 = To what extent do you have inner peace?; Sp7.2 = To what extent do are you hopeful about your life?; Sp8.2 = To what extent does faith give you comfort in daily life?; SRPB 9 = 9-item Spirituality, Religion, and Personal Beliefs assessment; wq6 = World Health Organization Quality of Life [WHOQOL-BREF] spirituality item (To what extent do you feel life to be meaningful?).

\section{Unidimensionality: Rasch analysis}

The unidimensionality of the instrument was analyzed using Rasch analysis. In the general model fit measures, the 9-item SRPB presented adequate statistical performance. The fit test results were considered good after only one adjustment to the response for item Sp1.1: "To what extent does any connection to a spiritual being help you get through hard times?" Category 1 (a little) and category 2 (a moderate amount) were collapsed (Figure 2). After this adjustment, this model showed a good fit. The item fit residual was $M=-0.30$ and $S D=1.94$, while the Person fit residual was $\mathrm{M}=-0.56$ and $\mathrm{SD}=1.57$. With respect to the item-trait relationship, the total item $\chi^{2}$ was $56.73 ; p=$ 0.112 . The person separation index was 0.84 . All residual values were within the acceptable range, and no items needed to be excluded for subsequent retesting.

\section{Classical psychometrics}

The response rate for the lowest response on the scale was $<10 \%$ for all items, i.e., there was no floor effect. However, the highest score was selected $>20 \%$ (range $22-34 \%$ ) for eight of the nine items, indicating a ceiling effect for almost all of the items, except Sp6.2: "To what extent do you have inner peace?"

Cronbach's alpha was used to measure internal consistency, which was considered good (total value of 0.85 ) after deleting items which varied from 0.82 to 0.85 . Internal consistency analysis was performed with all nine items, and the internal consistency calculation was repeated nine times, excluding one item each time (this is the reason for the variation in Cronbach's alpha).

The discriminant validity of the 9-item SRPB assessment differentiates between believers and atheists/agnostics $(\mathrm{M}=$ $74.7 \pm 14.1$ and $\mathrm{M}=56.8 \pm 15.5$, respectively; $t=6.37 ; \mathrm{df}=$ 402; $\mathrm{p}<0.01$ ) and between non-depressed and depressed individuals $(\mathrm{M}=76.5 \pm 12.7$ and $\mathrm{M}=67.1 \pm 16.5 ; t=5.57$; $\mathrm{df}=190.5 ; \mathrm{p}<0.01)$. The 9-item SRPB did not differentiate between healthy and unhealthy individuals $(\mathrm{M}=74.5 \pm 13.7$ and $\mathrm{M}=72.5 \pm 15$, respectively; $t=1.36 ; \mathrm{df}=387.7 ; \mathrm{p}=$ $0.174)$. Religious and non-depressed individuals showed significantly higher scores than the comparison group.

Convergent validity was assessed using Pearson's correlation between the 9-item SRPB assessment and the long-form SRPB domain (without the eight items included in the 9-item SRPB) and other valid measures of religiosity/ spirituality and QoL, namely the RCOPE scale and the WHOQOL-BREF (without the item included in the 9-item SRPB) (Table 2). Correlation with the long-form SRPB domain $(r=0.934)$ was almost perfect. Correlations were significant and in the positive direction with the positive-RCOPE subscale (large magnitude) and the WHOQOL-BREF (small-to-large magnitude), except for the negativeRCOPE subscale, for which the correlations were 


\section{A}

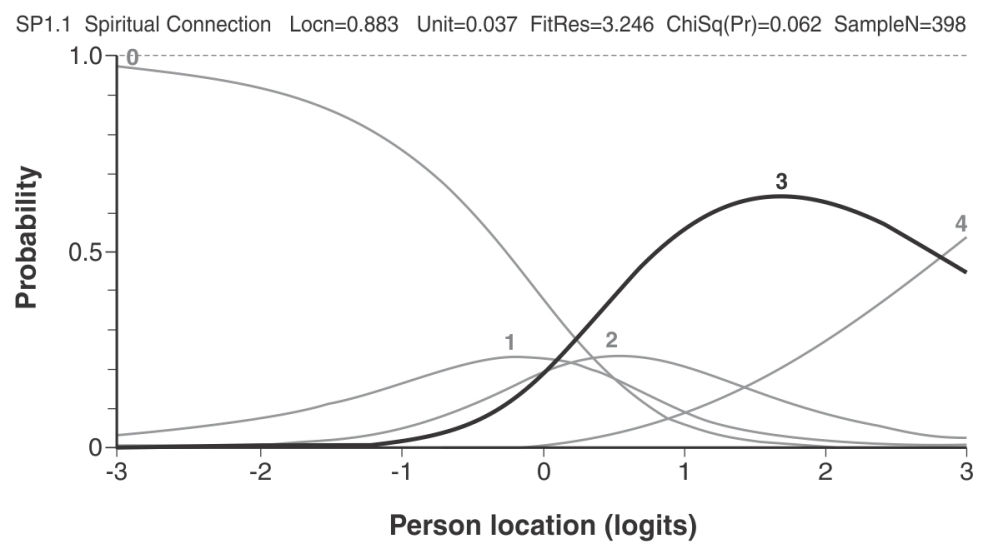

B

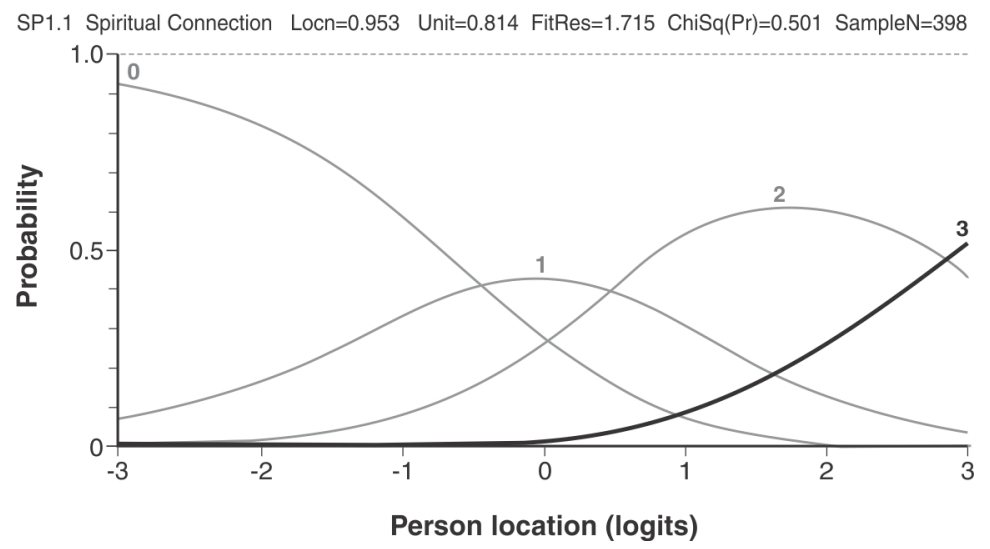

Figure 2 Item Sp1.1 before (A) and after (B) adjustment ("To what extent does any connection to a spiritual being help you get through hard times?"). The default Rasch analysis program transforms Likert scores (1 to 5) on a scale of 0 to $4.0=$ not at all; 1 = a little; 2 = a moderate amount; 3 = very much; 4 = an extreme amount.

Table 2 Convergent validity: Pearson correlation coefficients between 9-item SRPB assessment, the long-form SRPB domain, the Brief RCOPE Scale, and the WHOQOL domains

\begin{tabular}{lcc}
\hline Religiosity/Spirituality and QoL measures & $\begin{array}{c}\text { 9-item } \\
\text { SRPB }(r)\end{array}$ & $\begin{array}{c}\text { 9-item } \\
\text { SRPB }\left(r^{2}\right)\end{array}$ \\
\hline Long-form SRPB domain* & $0.934^{\ddagger}$ & 0.872 \\
& & \\
Brief RCOPE Scale & & \\
Positive-RCOPE subscale & $0.571^{\ddagger}$ & 0.326 \\
Negative-RCOPE subscale & $-0.101^{\S}$ & -0.010 \\
& & \\
WHOQOL-BREF domains ${ }^{\dagger}$ & & \\
Overall QoL & $0.279^{\ddagger}$ & 0.078 \\
Physical & $0.236^{\ddagger}$ & 0.056 \\
Psychological & $0.485^{\ddagger}$ & 0.235 \\
Social & $0.406^{\ddagger}$ & 0.165 \\
Environment & $0.327^{\ddagger}$ & 0.107 \\
\hline
\end{tabular}

QoL = quality of life; RCOPE = Religious and Spiritual Coping Questionnaire; SRPB = Spirituality, Religion and Personal Beliefs; WHOQOL-BREF = World Health Organization Quality of LifeAbbreviated version.

* Long-form SRPB without the eight items included in the 9-item SRPB.

WHOQOL-BREF without the item included in the 9-item SRPB. $\ddagger_{p}<0.01 ;{ }^{\S} p<0.05$. significant, but in the negative direction (small magnitude). The effect magnitudes followed Cohen's classification. ${ }^{24,25}$

\section{WHOQOL-BREF: psychometric properties}

The discriminant validity of the WHOQOL-BREF was assessed using a $t$-test. In this sample, all WHOQOL-BREF domains discriminated between healthy and unhealthy individuals in addition to all WHOQOL-BREF domains, except the social domain, (physical $[\mathrm{M}=76.0 \pm 12.8$ and $\mathrm{M}=50.5 \pm 19,5$, respectively; $t=-15.4 ; \mathrm{p}<0.01$ ]; psychological $[\mathrm{M}=72.6 \pm 13.0$ and $\mathrm{M}=64.4 \pm 17.1$, respectively; $t=-5.4 ; \mathrm{p}<0.01]$; social $[\mathrm{M}=70.1 \pm 17.9$ and $\mathrm{M}=68.8 \pm$ 18.4 , respectively; $t=-0.7 ; p=0.46]$; environmental $[\mathrm{M}=$ $62.7 \pm 12.6$ and $\mathrm{M}=58.2 \pm 15.2$, respectively; $t=-3.2$; $p<0.01]$; global $[M=73.4 \pm 14.4$ and $M=58.3 \pm 21.3$, respectively; $t=-8.3 ; p<0.01]$ ). All WHOQOL-BREF domains also discriminated between non-depressed and depressed individuals (physical $[\mathrm{M}=71.3 \pm 16.5$ and $\mathrm{M}=46.6 \pm 19.3$, respectively; $t=-12.4 ; \mathrm{p}<0.01]$; psychological $[\mathrm{M}=$ $74.5 \pm 10.8$ and $M=55.9 \pm 17.0$, respectively; $t=-11.2$; $\mathrm{p}<0.01$ ); social $[\mathrm{M}=73.9 \pm 15.8$ and $\mathrm{M}=59.5 \pm 19.2$, respectively; $t=-7.3 ; \mathrm{p}<0.01]$; environmental $[\mathrm{M}=$ 
64.8.0 \pm 11.9 and $\mathrm{M}=51.4 \pm 14.1$, respectively; $t=-9.2$; $\mathrm{p}<0.01]$; global $[\mathrm{M}=72.1 \pm 16.2$ and $\mathrm{M}=52.9 \pm 19.7$, respectively; $t=-15.4 ; \mathrm{p}<0.01])$. On the other hand, all WHOQOL-BREF domains did not discriminate between believers and atheists/agnostics (Physical $[\mathrm{M}=63.4 \pm$ 20.6 and $\mathrm{M}=67.1 \pm 23.4$, respectively; $t=-0.9 ; \mathrm{p}=0.37$; psychological $[\mathrm{M}=68.8 \pm 15.6$ and $\mathrm{M}=65.4 \pm 16.5$, respectively; $t=1.09 ; \mathrm{p}=0.28]$; social $[\mathrm{M}=69.5 \pm 17.8$ and $\mathrm{M}$ $=68.2 \pm 21.9$, respectively; $t=0.36 ; \mathrm{p}=0.72]$; environment $[\mathrm{M}=60.3 \pm 14.2$ and $\mathrm{M}=63.1 \pm 12.9$, respectively; $t=-0.98 ; \mathrm{p}=0.33]$; global $[\mathrm{M}=65.9 \pm 19.5$ and $\mathrm{M}=68.5 \pm$ 21.8 , respectively; $t=-0.68 ; p=0.50]$ ). Convergent validity was assessed using Pearson's correlation between WHOQOL-BREF and valid measures of depressive symptoms and religiosity/spirituality, namely the BDI and the RCOPE Scale. All WHOQOL-BREF domains correlated significantly and in the negative direction with the BDI (physical $r=-0.62$; psychological $r=-0.65$; social $r=-0.37$; environmental $r=-0.45$; global $r=-0.49$; $p<0.001$ ) (moderate-to-large magnitude) and with the negativeRCOPE subscale (physical $r=-0.32$; psychological $r=$ -0.37 ; social $r=-0.25$; environmental $r=-0.26$; global $r=$ -0.21; $p<0.001$ ) (small-to-moderate magnitude). Significant correlations between the WHOQOL-BREF and the positive-RCOPE subscale were mixed: there was an inverse correlation (small magnitude) between the physical domain and the positive-RCOPE subscale $(r=-0.12 ; p<$ 0.05), whereas there was a positive correlation (small magnitude) between the social domain and the positiveRCOPE subscale $(r=0.13 ; p<0.01)$. There was a positive but non-significant correlation between the psychological domain and the positive-RCOPE subscale $(r=$ $0.09, p=0.08$ ) and between the environmental domain and the positive-RCOPE subscale $(r=0.05, p=0.29)$.

\section{Discussion}

Outside the United Kingdom, this is the first study to assess the WHOQOL-SRPB BREF. The Brazilian Portuguese version of the 9-item SRPB assessment has good psychometric properties and confirmed the findings of its long-form version in Brazilian Portuguese ${ }^{9}$ and the abbreviated version in English. ${ }^{4}$ When applied to a Brazilian sample, the Brazilian Portuguese version of the 9-item SRPB assessment showed satisfactory factorial validity and unidimensionality, in addition to good internal consistency and discriminant and convergent validity.

The confirmatory factor analysis showed an acceptable fit to the data, in addition to an adequate contribution to the latent factor in each item. The number of adjustments required to achieve acceptable indices in confirmatory factor analysis was considered reasonable. Rasch analysis indicated unidimensionality. Since all items were acceptable in terms of residuals, no item was recommended for exclusion. In particular, item Sp1.1 appeared more problematic in both confirmatory factor analysis (lower loading $=0.37$ ) and Rasch analysis (two response categories were collapsed). Future analysis will be important to determine whether this item should remain in the instrument or be revised.
The internal consistency of the 9-item SRPB assessment, as measured by Cronbach's alpha coefficient, was very acceptable (alpha $=0.85$ ) compared to the English version (alpha $=0.83)^{4}$ and the Brazilian Portuguese longform SRPB domain (alpha $=0.96){ }^{9}$ The variation was 0.82 to 0.85 when an item was deleted. This shows that each item had similar importance in constructing the instrument, with none predominating over the others. The high Cronbach's coefficient indicates that the selected items are the core items of the spiritual QoL measure. It indicates that the 9-item SRPB assessment measures the spiritual QoL construct satisfactorily as a reliable and unidimensional measure.

Regarding discriminant validity, the 9-item SRPB assessment differentiated between believers and atheists/agnostics and between non-depressed and depressed individuals, as did the Brazilian 132-item long-form version, ${ }^{9}$ with the highest scores for religious and nondepressed individuals, as expected. The 9-item SRPB assessment did not differentiate between healthy and unhealthy individuals. This finding is probably related to the fact that spirituality is a more constant variable/construct in a person's life, regardless of health status. ${ }^{26,27}$ Skevington et al. ${ }^{4}$ emphasized that "the WHOQOL-SRPB BREF is an ideal tool to use in primary care because it can assess almost every type of patient, irrespective of their health state and status. As sick and well completion times were not different, it is pragmatic to use the WHOQOL-SRPB BREF in a variety of health, social and educational contexts, and this should be explored."

According to Pearson's correlation, convergent validity between the 9-item SRPB assessment and the long-form SRPB domain (without the eight items included in the 9-item SRPB) was practically perfect: $r=0.934$. This confirms the excellent psychometric profiles of the items selected for the abbreviated version. All Pearsons' correlations for convergent validity between the 9-item SRPB assessment, the Brief RCOPE Scale and the WHOQOLBREF (without the item included in the 9-item SRPB) were significant and in the positive direction, similar to the Brazilian Portuguese long-form SRPB domain findings. ${ }^{9}$ The exception was the correlation between 9-item SRPB assessment and the negative-RCOPE subscale, which was significant but in the negative direction (Table 2). This was expected since the negative-RCOPE subscale measures religious/spiritual aspects that are unfavorable for coping with stressful situations, that is, they are in the opposite direction of spiritual QoL ${ }^{13}$ (Table 2).

An unexpected feature that emerged from testing this spiritual QoL instrument was the ceiling effect. The highest possible response was selected $>20 \%$ of the time in eight of the nine items (ranging from $22 \%$ to $34 \%$ ), except item Sp6.2: "To what extent do you have inner peace?". Ceiling and floor effects are the percentage of subjects who scored the highest or the lowest possible scores, respectively, and are considered substantial if $\geqslant 20 \%$. ${ }^{21}$ This ceiling effect is probably related to the high religious indices of the Brazilian population. ${ }^{28}$

The 26-items of the Brazilian Portuguese WHOQOLBREF showed good psychometric properties in this sample, confirming the findings of its previous validation (Rocha \& 
Fleck). ${ }^{8,29}$ The WHOQOL-BREF discriminated between healthy and unhealthy individuals, but did not discriminate between believers and atheists/agnostics, which is suitable for an instrument that evaluates general QoL. Convergent validity analysis with the WHOQOL-BREF showed inverse correlations with depressive symptoms, as expected. ${ }^{30}$ Correlations between WHOQOL-BREF domains with the positive-RCOPE subscale were positive, except the physical domain, indicating that the presence of physical symptoms is associated with greater use of positive religious coping strategies. This point agrees with findings that a perception of being physically ill tends to increase am individual's use of religious/spiritual resources. ${ }^{26}$

We extracted the 9-item SRPB assessment from the validation database of the Brazilian Portuguese long-form SRPB domain. The fact that the participants did not exclusively fill out the WHOQOL-SRPB BREF is a limitation because the nine items cannot be used individually, since they do not assess the whole concept of QoL. Thus, whether in academic or healthcare services, to be sure that the results are reliable and valid in accordance with published values, all 34 items of the WHOQOL SRPB BREF must be administered together.

In conclusion, the Brazilian Portuguese 9-item SRPB assessment has good psychometric properties and confirms the findings of its long-form version in Brazilian Portuguese and the abbreviated version in English. These findings confirm our hypothesis and are in line with the cross-cultural nature of the WHOQOL Group's instruments. Correct application of the 9-item SRPB assessment should occur together with the other dimensions of the QoL in the WHOQOL-BREF, which results in the 34-item WHOQOL-SRPB BREF instrument.

\section{Acknowledgements}

This study received support from the Conselho Nacional de Desenvolvimento Científico e Tecnológico (CNPq) and the Fundo de Incentivo à Pesquisa - Hospital de Clínicas de Porto Alegre (FIPE-HCPA). We would like to thank Professor Suzanne Skevington, of the Manchester Centre for Health Psychology, School of Psychology Sciences, University of Manchester, Manchester, UK, for reviewing the text and providing precious suggestions.

\section{Disclosure}

The authors report no conflicts of interest.

\section{References}

1 Skevington SM. Advancing cross-cultural research on quality of life: observations drawn from the WHOQOL development. World Health Organisation quality of life assessment. Qual Life Res. 2002;11:135-44.

2 O'Connell KA, Skevington SM. The Relevance of spirituality, religion and personal beliefs to health-related quality of life: themes from focus groups in Britain. Br J Health Psychol. 2005;10:379-98.

3 WHOQOL SRPB Group. A cross-cultural study of spirituality, religion, and personal beliefs as components of quality of life. Soc Sci Med. 2006;62:1486-97. Epub 2005 Sep 13.

4 Skevington SM, Gunson KS, O'Connell KA. Introducing the WHOQOL-SRPB BREF: developing a short-form instrument for assessing spiritual, religious and personal beliefs within quality of life. Qual Life Res. 2013;25:1073-83. Epub 2012 Jul 27.
5 Development of the World Health Organization WHOQOL-BREF quality of life assessment. Psychol Med. 1998;28:551-8.

6 Skevington SM, Lotfy M, O'Connell KA; WHOQOL Group. The World Health Organization's WHOQOL-BREF quality of life assessment: psychometric properties and results of the international field trial. A report from the WHOQOL group. Qual Life Res. 2004;13:299-310.

7 Skevington SM, Epton T. How will the sustainable development goals deliver changes in well-being? A systematic review and metaanalysis to investigate whether WHOQOL-BREF scores respond to chang. BMJ Glob Health. 2018;3(Suppl 1):e000609.

8 Fleck MPA, Louzada S, Xavier M, Chachamovich E, Vieira G, Santos $\mathrm{L}$, et al. [Application of the Portuguese version of the abbreviated instrument of the quality of life WHOQOL-bref]. Rev Saude Publica. 2000;34:178-83.

9 Panzini RG, Maganha C, Rocha NS, Bandeira DR, Fleck MP. Brazilian validation of the quality of life instruments/spirituality, religion and personal beliefs. Rev Saude Publica. 2011;45:153-65.

10 Pierucci AF, Prandi R. A realidade social das religiões no Brasil. São Paulo: Hucitec; 1996.

11 Fleck MPA, Borges ZM, Bolognesi G, Rocha NSda. Desenvolvimento do WHOQOL, módulo espiritualidade, religiosidade e crenças pessoais. Rev Saude Publica. 2003;37:446-55.

12 Pargament KI, Koenig HG, Perez LM. The many methods of religious coping: development and initial validation of the RCOPE. J Clin Psychol. 2000;56:519-43.

13 Panzini RG, Bandeira DR. Escala de coping religioso-espiritual (Escala CRE): elaboração e validação de construto. Psicol Estud. 2005;10:507-16.

14 Cunha JA. Manual da versão em português das Escalas de Beck. São Paulo: Casa do Psicólogo; 2001.

15 Hair JF Jr, Black W, Babin B, Anderson R, Tatham R. Análise multivariada de dados. $6^{a}$ ed. São Paulo: Bookman; 2009.

16 Chen F, Curran PJ, Bollen KA, Kirby J, Paxton P. An empirical evaluation of the use of fixed cutoff points in RMSEA test statistic in structural equation models. Sociol Methods Res. 2008;36:462-94.

17 Hutz CS, Bandeira DR, Trentini CM. Psicometria. Porto Alegre: Artmed; 2015.

18 Camey S, Fachel J. Avaliação psicométrica: a qualidade das medidas e o entendimento dos dados. In: Cunha JA, editor. Psicodiagnóstico V. Porto Alegre: Artmed; 2008. p.158-70.

19 Tennant A, McKenna SP, Hagell P. Application of Rasch analysis in the development and application of quality of life instruments. Value Health. 2004; 7:S22-6.

20 Rocha NS, Power MJ, Bushnell DM, Fleck MP. Cross-cultural evaluation of the WHOQOL-BREF domains in primary care depressed patients using Rasch analysis. Med Decis Making. 2012;32:41-55.

21 Ware JE Jr, Sherbourne CD. The MOS 36-item short-form health survey (SF-36). I. Conceptual framework and item selection. Med Care. 1992;30:473-83.

22 Cronbach LJ. Coefficient alpha and the internal structure of tests. Psychometrika. 1951;16:297-334.

23 Associação Brasileira de Empresas de Pesquisa (ABEP). Critério de classificação econômica Brasil [Internet]. [cited 2015 Mar 25]. http:// www.abep.org/criterio-brasil

24 Cohen J. Statistical power analysis for the behavioral sciences. 2nd ed. New Jersey: Lawrence Erlbaum; 1988.

25 Gignac GE, Szodorai ET. Effect size guidelines for individual differences researchers. Pers Individ Dif. 2016;102:74-8.

26 Rocha NS, Fleck MPA. Evaluation of quality of life and importance given to spirituality/religiosity/personal beliefs (SRPB) in adults with and without chronic health conditions. Rev Psiquiatr Clin. 2011;38:19-23.

27 Panzini RG. Qualidade de vida, espiritualidade, saúde e coping: validação do WHOQOL-SRPB em português brasileiro e estudo longitudinal de tratamento para transtorno de pânico [doctoral thesis]. Porto Alegre: Universidade Federal do Rio Grande do Sul; 2013.

28 Instituto Brasileiro de Geografia e Estatística (IBGE). Censo demográfico 2010 [Internet] [cited 2018 Oct 31]. http://ww2.ibge.gov.br/ home/estatistica/populacao/censo2010

29 Rocha NS, Fleck MP. Validity of the Brazilian version of WHOQOLBREF in depressed patients using Rasch modelling. Rev Saude Publica. 2009:43:147-53.

30 Rocha NS, Fleck MP. Evaluation of quality of life in adults with chronic health conditions: the role of depressive symptoms. Rev Bras Psiquiatr. 2010;32:119-24. 